\title{
Complete mitochondrial DNA and phylogenetic study of qionglai native black chicken
}

\author{
Yaodong Hu, Yun Zhu, Huizhong Pang, Dan Lan \\ Farm Animal Genetic Resources Exploration and Innovation Key Laboratory of Sichuan Province, Sichuan Agricultural University, Ya'an, \\ Sichuan 625014, China
}

\begin{abstract}
The complete mitochondrial genome sequence of the qionglai black chicken was measured by PCR-based methods, the molecular characterization and phyletic evolution analyzed in detail. Our result showed that the entire mitochondrial genome of the qionglai black chicken is a circular molecule consisting of 16,785 bp (GenBank accession number: KT958484). The contents of A, T, C, and G were $30.25 \%, 23.74 \%$, $32.54 \%$ and $13.48 \%$ in the mitochondrial genome, respectively. The complete mitochondrial genome of the qionglai black chicken contains a typical structure, including 13 protein-coding genes, 2 rRNA genes, 22 tRNA genes and 1 control region (D-loop region). The phyletic evolution analysis shown that this chicken was evolution between the red jungle fowl and the special egg chicken white loghorn chicken. This complete mitochondrial genome sequence provides essential information in understanding phylogenetic relationships among Gallus gallus domesticus mitochondrial genomes and the breeding of native chick
\end{abstract}

\section{Introduction}

In China, indigenous chickens making up $20 \%$ of the poultry market, and the indigenous chicken market is rapidly developing by a rate of 5 to $10 \%$ per year[1]. Native black chicken is one of the famous Chinese indigenous chickens in Sichuan province, and it has a large number of breeding in qionglai city which was called as qionglai black chicken. The qionglai black chicken, which has black feathers, black skin and red comb. The qionglai black chicken as the importance indigenous breed and genetic resource was a valuable resource for preserve genetic diversity.

Recently, the chicken market was occupied by specialied commercial populations, which originated in foreign countries. It was the enormous impact for the indigenous chicken market. Qionglai black chicken as the indigenous breeds was a large genetic resousrces as well as having well-adapted and stress toletant as its advantage. While it also have some disadvantage like low production performance. therefore, taking full advantage of this breeds was importance for the indgenous chicken breeding and save the gentic diversity .

Mitochondrial DNA(mtDNA) have the characteristic of quick evolution, matrilineal inherritance and simple molecular structure, which was the most being used as the molecular study marker. Recently, many studies have reported the results of using the fine-gained complete mtDNA to analyses and reconstruct the history of animal domestication, such as horses, pigs and cattle[2-7] .in this study, we research the mtDNA of qionglai black chicken to understanding it characterisric and phylogenetic.

\section{Material and Methods}

A total of 15 qionglai black chicken were sampled for this study, All birds were reared under the same condition: cage free (density of $<35$ chicken/100 m 2 ) and standard conditions of temperature $\left(20^{\circ}\right.$ to $\left.22^{\circ} \mathrm{C}\right)$, relative humidity (55 to $60 \%$ ), and ventilation were maintained. The chickens were fed the same professional breeder diet and had free access to feed and water during the entire rearing period. Birds were managed with full consideration of bird welfare. All procedures involving animals were approved by the Institutional Animal Care and Use Committee of the National Institute of Agrobiological Sciences.

\subsection{Sample collection}

Approximately $2 \mathrm{~mL}$ blood was collected from the brachial vein of each individual according to the requirements of animal welfare of Sichuan Agricultural University, and stored at $-20^{\circ} \mathrm{C}$. The next day, genomic DNA was isolated by phenolic extraction. The quality and integrity of DNA was assessed using the A260/280 ratio and agarose gel electrophoresis.

\subsection{Data Analysis}


The complete mitochondrial genome was amplified by 22 pairs of primers designed according to the sequence of the Gallus gallus (GenBank accession number: AP003322). To determine whether the sequences obtained were correct, an NCBI nucleotide BLAST search was conducted (http://blast.ncbi.nlm.nih.gov/). The DNA sequence was analyzed using DNAStar 7.1 software (Madison, MI) and the base composition and distribution of the mitochondrial DNA sequence were analyzed using tRNA Scan-SE1.21 software (http://lowelab.ucsc.edu/tRNAScan-SE/)[8] and DOGMA software (http://dogma.ccbb.utexas.edu/) [9], the phylogenetic were analyzed by mega4.1, respectively.

\section{Results and Discussion}

\subsection{The stucture of the mtDNA}

We submission the sequence to the NCBI(http://www.ncbi.nlm.nih.gov/ ) and the genbank accession number was KT958484.The complete mitochondrial DNA of qionglai native chicken was $16785 \mathrm{bp}$ which contain 13 protein-coding genes, 22 transfer RNA genes, 2 ribosomal RNA genes and 1 control region (D-loop region). The gene arrangement and composition were similar to those of other avian species[10,11]. The overall nucleotide composition of $\mathrm{A}, \mathrm{T}, \mathrm{C}$ and $\mathrm{G}$ were found to be $30.28 \%, 23.74 \%$, $32.50 \%$ and $13.48 \%$, respectively, and in the order $\mathrm{C}>\mathrm{A}>\mathrm{T}>\mathrm{G}$. Most of the genes are encoded on the $\mathrm{H}$-strand and they are similar in structure to the typical mitochondrial genome of vertebrates[12].

The molecular characterization of qionglai black chicken mitochondrial genome as followed (Table 1). Firstly, the initiation codon of the protein -coding genes is ATG, except for COX1, which show a GTG initiation codon. Secondly, have nine genes not encoded on the L-stand, including 1 protein-coding gene (ND6) and 8 tRNA genes (tRNA-Gln, tRNA-Ala, tRNA-Asn, tRNA-Cys, tRNA-Tyr, tRNA-Ser, tRNA-Pro and tRNA-Glu). Thirdly, these genes have four different types of termination codons: TAA AGG TAG and T--. Among all gene elements, there were overlaps and spaces. The D-loop contains regulatory elements that control mtDNA replication and transcription, which is a non-coding control region located between the tRNA-Glu and tRNA-Phe genes, and rich in $\mathrm{A}$ and $\mathrm{T}$.

\subsection{Phylogenetic analysis}

We alignment the sequence of qionglai black chicken and other gallus (red jungle fowl, Ceylon jungle fowl, Green jungle fowl, grey jungle fowl, white leghorn), the outgroup were meleagris gallopavo, aix galericulata, alectoris chukar and tadorna ferruginea, the evolution tree shown that the qionglai black chicken phyletic evolution was between the red jungle fowl and white leghorn(Figure 1). As the results shwon, we speculate that the qionglai black chicken was suitable for developent in egg production.

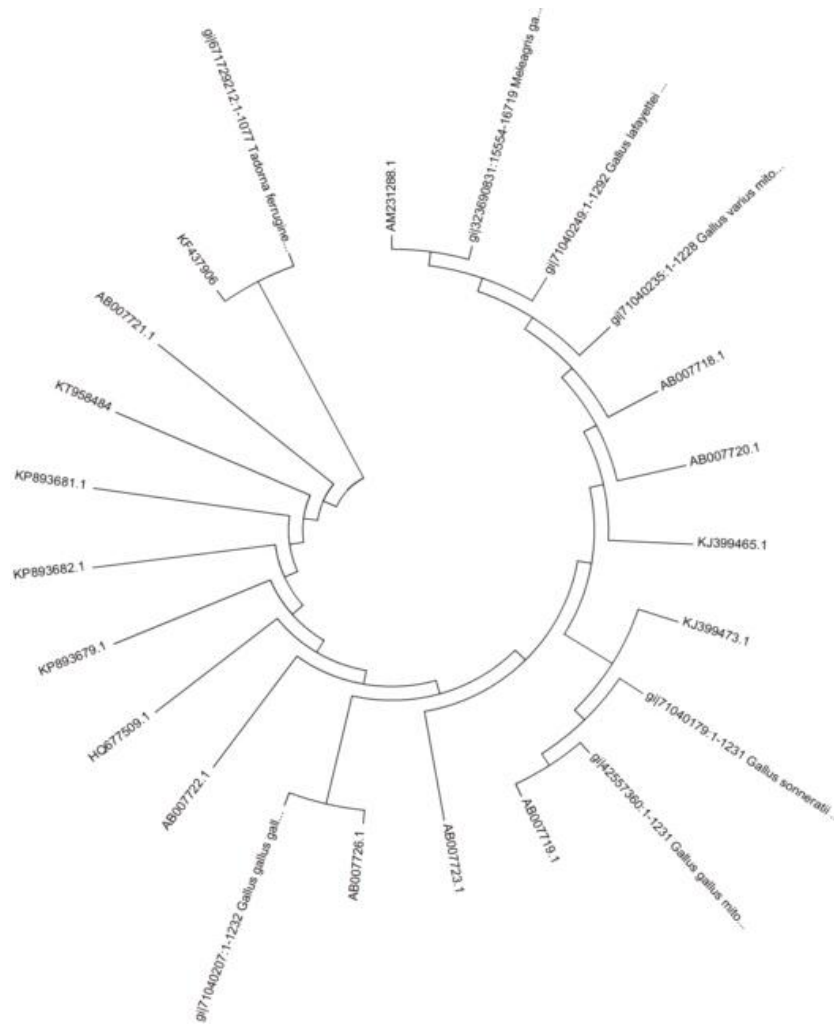

Figure 1. The Unrooted neighbor-joining (NJ) tree of qionglai black chicken and others.

Table 1. The molecular characterization of qionglai black chicken mtDNA

\begin{tabular}{|c|c|c|c|c|c|c|c|c|}
\hline \multirow{2}{*}{ Gene } & \multicolumn{2}{|c|}{ Position } & \multirow[b]{2}{*}{ size } & \multicolumn{3}{|c|}{ codon } & \multirow[b]{2}{*}{$\operatorname{stand}(\mathrm{H} / \mathrm{L})$} & \multirow{2}{*}{ space $(+) /$ ovrelap $(-)$} \\
\hline & start & end & & start & stop & anti & & \\
\hline \multirow{2}{*}{ D-loop } & 1 & 1162 & \multirow{2}{*}{1232} & & & & \multirow{2}{*}{$\mathrm{H}$} & \multirow{2}{*}{0} \\
\hline & 16716 & 16785 & & & & & & \\
\hline tRNA-Phe & 1163 & 1231 & 69 & & & GAA & $\mathrm{H}$ & 0 \\
\hline $12 \mathrm{~S}$ rRNA & 1232 & 2207 & 976 & & & & $\mathrm{H}$ & 0 \\
\hline tRNA-Val & 2208 & 2280 & 73 & & & GAC & $\mathrm{H}$ & 0 \\
\hline 16S rRNA & 2281 & 3902 & 1622 & & & & $\mathrm{H}$ & 0 \\
\hline tRNA-Leu & 3903 & 3976 & 74 & & & GAG & $\mathrm{H}$ & 0 \\
\hline ND1 & 3986 & 4960 & 975 & ATG & TAA & & $\mathrm{H}$ & 9 \\
\hline
\end{tabular}




\begin{tabular}{|c|c|c|c|c|c|c|c|c|}
\hline tRNA-Ile & 4961 & 5032 & 72 & & & GAT & $\mathrm{H}$ & 0 \\
\hline tRNA-Gln & 5038 & 5108 & 71 & & & TTG & $\mathrm{L}$ & 5 \\
\hline tRNA-Met & 5108 & 5176 & 69 & & & CAT & $\mathrm{H}$ & -1 \\
\hline ND2 & 5177 & 6217 & 1041 & ATG & TAG & & $\mathrm{H}$ & 0 \\
\hline tRNA-Trp & 6216 & 6291 & 76 & & & $\mathrm{CCA}$ & $\mathrm{H}$ & -2 \\
\hline tRNA-Ala & 6298 & 6366 & 69 & & & AGC & $\mathrm{L}$ & 6 \\
\hline tRNA-Asn & 6370 & 6442 & 73 & & & ATT & $\mathrm{L}$ & 3 \\
\hline tRNA-Cys & 6444 & 6509 & 66 & & & GCA & $\mathrm{L}$ & 1 \\
\hline tRNA-Tyr & 6509 & 6579 & 71 & & & GTA & $\mathrm{L}$ & -1 \\
\hline COI & 6581 & 8131 & 1551 & GTG & AGG & & $\mathrm{H}$ & 1 \\
\hline tRNA-Ser & 8123 & 8197 & 75 & & & TGA & $\mathrm{L}$ & -9 \\
\hline tRNA-Asp & 8200 & 8268 & 69 & & & GTC & $\mathrm{H}$ & 2 \\
\hline COII & 8270 & 8953 & 684 & ATG & TAA & & $\mathrm{H}$ & 1 \\
\hline tRNA-Lys & 8955 & 9022 & 68 & & & CTT & $\mathrm{H}$ & 1 \\
\hline ATPase 8 & 9024 & 9188 & 165 & ATG & TAA & & $\mathrm{H}$ & 1 \\
\hline ATPase 6 & 9179 & 9862 & 684 & ATG & TAA & & $\mathrm{H}$ & -10 \\
\hline COIII & 9862 & 10645 & 784 & ATG & TAA & & $\mathrm{H}$ & -1 \\
\hline tRNA-Gly & 10647 & 10714 & 68 & & & $\mathrm{ACC}$ & $\mathrm{H}$ & 1 \\
\hline ND3 & 10716 & 11066 & 351 & ATG & TAA & & $\mathrm{H}$ & 1 \\
\hline tRNA-Arg & 11068 & 11135 & 68 & & & TCT & $\mathrm{H}$ & 1 \\
\hline ND4L & 11136 & 11432 & 297 & ATG & TAA & & $\mathrm{H}$ & 0 \\
\hline ND4 & 11426 & 12803 & 1378 & ATG & TAT & & $\mathrm{H}$ & -5 \\
\hline tRNA-His & 12804 & 12872 & 69 & & & ATG & $\mathrm{H}$ & 0 \\
\hline tRNA-Ser & 12874 & 12938 & 65 & & & GCT & $\mathrm{H}$ & 1 \\
\hline tRNA-Leu & 12940 & 13010 & 71 & & & AAG & $\mathrm{H}$ & 1 \\
\hline ND5 & 13011 & 14828 & 1818 & ATG & TAA & & $\mathrm{H}$ & 0 \\
\hline cytb & 14833 & 15975 & 1143 & ATG & TAA & & $\mathrm{H}$ & 4 \\
\hline tRNA-Thr & 15979 & 16047 & 69 & & & TGA & $\mathrm{H}$ & 3 \\
\hline tRNA-Pro & 16048 & 16117 & 70 & & & TGG & $\mathrm{L}$ & 0 \\
\hline ND6 & 16124 & 16645 & 522 & ATG & TAA & CAT & $\mathrm{L}$ & 6 \\
\hline tRNA-Glu & 16648 & 16715 & 68 & & & TTC & $\mathrm{L}$ & 2 \\
\hline
\end{tabular}

\section{Acknowledgments}

This work was supported by the program for the key project from education department of Sichuan Province (14ZA0021), the project of the application basis project from the science and technology department of Sichuan province (2014JY0163), and the project of national natural science foundation of china (31402068).

\section{References}

1. Tang, H., et al., Variation of meat quality traits among five genotypes of chicken. Poultry science, 2009. 88(10): p. 2212-2218.

2. Achilli, A., et al., The multifaceted origin of taurine cattle reflected by the mitochondrial genome. PloS one, 2009. 4(6): p. e5753.

3. Achilli, A., et al., Mitochondrial genomes of extinct aurochs survive in domestic cattle. Current Biology, 2008. 18(4): p. R157-R158.
4. Achilli, A., et al., Mitochondrial genomes from modern horses reveal the major haplogroups that underwent domestication. Proceedings of the National Academy of Sciences, 2012. 109(7): p. 2449-2454.

5. Bonfiglio, S., et al., The enigmatic origin of bovine mtDNA haplogroup $R$ : sporadic interbreeding or an independent event of Bos primigenius domestication in Italy? PloS one, 2010. 5(12): p. e15760.

6. Pang, J.-F., et al., mtDNA data indicate a single origin for dogs south of Yangtze River, less than 16,300 years ago, from numerous wolves. Molecular biology and evolution, 2009. 26(12): p. 2849-2864.

7. Wu, G.-S., et al., Population phylogenomic analysis of mitochondrial DNA in wild boars and domestic pigs revealed multiple domestication events in East Asia. Genome Biol, 2007. 8(11): p. R245.

8. Lowe, T.M. and S.R. Eddy, tRNAscan-SE: a program for improved detection of transfer RNA genes in genomic sequence. Nucleic acids 
research, 1997. 25(5): p. 0955-964.

9. Wyman, S.K., R.K. Jansen, and J.L. Boore, Automatic annotation of organellar genomes with DOGMA. Bioinformatics, 2004. 20(17): p. 3252-3255.

10. Yan, M.-L., et al., The complete mitochondrial genome sequence of the Daweishan Mini chicken. Mitochondrial DNA, 2014(0): p. 1-2.
11. Bao, H., et al., Sequencing and alignment of mitochondrial genomes of Tibetan chicken and two lowland chicken breeds. Science in China Series C: Life Sciences, 2008. 51(1): p. 47-51.

12. Boore, J.L., Animal mitochondrial genomes. Nucleic acids research, 1999. 27(8): p. 1767-1780. 